\title{
POST-CRISIS POTENTIAL OUTPUT IN THE WESTERN BALKANS
}

Naida Čaršimamović Vukotić, Irena Jankulov Suljagić, Irina Smirnov *

\begin{abstract}
Spurred by the recent global economic crisis, there has been a resurgence of research on output gaps. As the crisis caused a decline in potential GDP due to a strong contraction in demand, it is expected that the recovery of potential output will be especially difficult in demand-driven small open economies, such as the Western Balkan countries, where recovery will strongly depend on global international trade recovery. The purpose of this research is to calculate and compare pre and post-crisis potential GDPs and GDP gaps for the Western Balkan countries. The symmetric filter method developed by Hodrick and Prescott is used to de-trend GDP time series data by decomposing it into growth and cyclical components. The results point to a strong decrease in potential output growth compared to the pre-crisis potential output growth of the Western Balkans.
\end{abstract}

Keywords: Potential output, Output gap, Crisis, Western Balkans, HP filter

JEL classification: E32

South East European Journal of Economics and Business

Volume 8 (1) 2013, 23-33

DOI: $10.2478 /$ jeb-2013-0002

\section{INTRODUCTION}

Output gap measures the difference between potential and actual output. Potential output of a country is a macroeconomic indicator measuring the equilibrium level of output related to long term aggregate supply and the ultimate level of gross domestic product (GDP) under the assumption of no transitory shocks and no price and wage rigidities. Consequently, the importance of proper approximation of the potential output cannot be overestimated, since it gauges the level of the maximum sustainable economic growth of a country and is used to cyclically adjust monetary and fiscal indicators to examine levels that would occur in the absence of inflationary expansion and recession.

Most structural macroeconomic models used for forecasting and policy analyses require an estimate of potential output. In these models, the gap between actual and potential output is a key variable determining the evolution of prices and wages. A level of real GDP above potential will often be seen as a source of inflationary pressures and a signal that the monetary authorities should tighten their policy, and vice versa. The output gap then corresponds to the transitory component of output.

Potential output can also be a useful indicator for policymakers in adopting appropriate measures in response to

a crisis. Knowledge of the cyclical position - based on estimates of potential output and the position of GDP in relation to its potential - is a key element in monetary and fiscal frameworks. First, the level of GDP relative to its potential has implications for inflationary pressures in the economy. Second, the size and sign of the output gap provides a good indicator of an economy's cyclical position, which is

\section{* Naida Čaršimamović Vukotić}

Budget Expert

World Bank Public Expenditure Management Peer Assisted Learning Network

E-mail: naidacar@gmail.com

\section{Irena Jankulov Suljagić}

Senior Economist

International Monetary Fund Resident Representative Office to $\mathrm{BiH}$

E-mail: irena.jankulov@gmail.com

\section{Irina Smirnov}

Economic Adviser, European Union Delegation to $\mathrm{BiH}$

E-mail: irinas@gnet.ba 
an important element in the estimation of the structural fiscal balance. Potential output estimates may also point to the necessary overall direction for general macroeconomic policy, with large gaps implying that existing production factors are not utilized well and exhausted gaps implying that the economy may need more fundamental structural change (IMF 2009).

Having in mind the current recession-riddled global economic environment, examination of potential output levels and their changes in comparison to the pre-crisis levels is particularly timely and insightful. Empirical research shows that recessions associated with financial turmoil significantly reduce potential output, and in addition, it is expected that developing (non-advanced) countries in Europe will see a particularly strong reduction in potential output due to capital inflow reduction, the additional volatility in risk premium negatively affecting investment, as well as due to labor market mismatches and over-heated pre-crisis growth arising, for example, from real estate and construction booms (IMF 2009a).

According to IMF (2011b) research on the impact of the global crisis on South-Eastern Europe, "the crisis exerted a significant and, in some key respects, lasting impact on these countries". The study finds that the SEE region experienced macroeconomic adjustments that could be grouped in three main categories: (i) current account correction, (ii) more difficult financing and credit conditions, and (iii) deterioration in public finances. On top of these macroeconomic turbulences, the crisis stripped down domestic weakness and exposed problems with the countries' growth model. Growth potential has been held down by delays in advancing structural reforms needed to address sizable external imbalances (EBRD 2009, pg.56).

In terms of possible policy implications, it is clear that the crisis hit the Western Balkans at a time when the countries' growth model - which relied on strong capital inflows, rapid credit expansion, and consumption-based domestic demand - had already been put into question. In the precrisis period, the region benefited from this model having higher real and potential output growth rates, which have now been halved. With rising external imbalances, domestic weaknesses have been revealed and restoring precrisis growth rates now depends on new growth engines (Daviddi, Carsimamovic Vukotic, and Smirnov 2012), which in turn rely on on implementing "good" policies promptly. This requires adoption of appropriate macroeconomic and structural policies. Sound macroeconomic policies can contribute to the stability of the economy and provide a framework for a recovery to take place. Although structural reforms are country-specific, measures aimed at improving the business environment, educating, restructuring and enhancing labor supply, reforming product markets, and stimulating research and development all need to be considered. In other words, human capital and total factor productivity gains will play a major role in the growth potentials of the WB countries.

The purpose of this research is to calculate and compare pre-crisis and post-crisis potential GDPs and GDP gaps for the Western Balkan (WB) countries of Albania,
Bosnia and Herzegovina (BiH), Croatia, Kosovo, Macedonia, Montenegro, and Serbia. The paper uses a symmetric filter method developed by Hodrick and Prescott (HP), which detrends GDP time series data by decomposing it into growth and cyclical components. The paper is organized as follows: Section 2 defines potential output, gives a literature review in the field of measuring potential output, and provides an overview of approaches to estimating potential output. Section 3 provides a rationale for the application of the approach used in the paper and a description of its methodology - a statistical de-trending tool. Section 4 describes the data used in the research, as well as the results and explanations of the empirical research. Finally, Section 5 offers conclusions stemming from the research.

\section{THEORETICAL FRAMEWORK AND LITERATURE REVIEW}

\subsection{What is Potential Output?}

Despite the fact that the potential output concept is widely used by economists, there are different opinions as to how exactly potential output should be defined. In statistical terms, potential output is a trend output (Ladiray, Mazzi, and Sartori 2003). The theoretical view is that potential output is based on the supply side of the economy and, as such, is defined as the production level at the normal utilization of factors of production at the current state of technology (Castle 2003). Subsequently, the output gap - thought of as a consequence of demand shocks - would equal the transitory component of output (Campbell and Mankiw 1987). As the shock is absorbed by the economy, the economy should return towards its steady state. In other words, potential output can also be considered to be the steady state level of output associated with the long-run aggregate supply curve. Often, potential output is referred to as the production capacity of the economy (Jahan and Mahmud 2013).

In literal terms, the potential output would mean the maximum possible output of an economy if all of its resources were fully employed. One such extreme definition of potential output (Gibbs 1995) would be the output that is associated with a situation in which everyone of working age worked 24 hours per day, every day of the year. This concept broadly corresponds to what is also referred to in the literature as 'efficient output' (Fueki, Fukunaga, Ichiue and Shirota 2010), defined as the level of output in an environment without nominal rigidities in goods and labor markets and without shocks to price and wage markups (Mishkin 2007). Under this concept, the potential output moves closely with the actual output and is more volatile than conventional measures of potential output.

Alternatively, the term 'potential output' can be defined as some normal level of production given an 'average' factor utilization rate (Mazi 1997). In line with this approach, the potential output of an economy is defined as the maximum level of output obtainable without generating an increase in inflation. In this case, calculations of potential output are based either explicitly or implicitly on estimates of the 
natural rate of unemployment, i.e. 'the rate of unemployment which prevails when expectations of inflation are realized, and toward which the economy will tend to converge following a disturbance' (Friedman 1968).

Regardless of the theoretical differences in terms of the definition of potential output, both potential output and the corresponding output gap - defined as the difference between potential and actual output expressed as a share of potential output - are latent variables that cannot be observed directly (Kutner 1994, Parigi and Siviero 2001).

\subsection{Review of the Research on Potential Output in the Western Balkans}

In contrast to studies covering developed countries, there are relatively few empirical studies of the potential output in developing countries, due to issues with the availability and/or quality of data (De Masi 1997). Most of the available studies for developing countries deal with East-Asian countries, and are not conclusive in terms of the overall size of output gaps, regardless of the methodology used (HP filter and production function approaches are commonly used). Cerra and Saxena (2008) show that crises produce a significant and permanent loss in the level of output compared with the pre-crisis trend and that it is thus generally likely that developing countries' potential output has fallen in the current crisis.

The region of the Western Balkans includes transition countries for which studies are scarce, since calculation of potential output is further complicated due to the fact that the time series data is short spanned. Thus, for these countries, research is limited to first constructing medium- to long-term growth projections and then applying one of the calculation approaches (De Masi 1997).

Studies and papers calculating output gaps for the Western Balkan countries are mostly limited to calculations by international financial institutions, such as the International Monetary Fund and World Bank, performed as one of the indicators of the overall macroeconomic frameworks of these countries. The World Bank (2010) estimates that around $5.5 \%$ percentage points of potential output growth rates was lost in the Western Balkan countries in 2009 and 2010. There are no scholarly journal articles that look specifically at all of the Western Balkan countries and calculate and compare their potential outputs.

Given the fact that potential output cannot be observed directly, the question emerges of whether several years of strong growth should be interpreted as a new long run steady trend, or whether in fact it represented unsustainable growth. According to Darvas (2011), the 2008-2009 crisis has also altered the future growth prospects of the countries of Central and Eastern Europe, the Caucasus and Central Asia even in the optimistic case of a return to pre-crisis capital inflows and credit booms. This issue was in particular associated with emerging European economies, as catching up with the output levels of advanced economies has rarely been a steady process but often involved much variation (IMF 2009). With the EU's potential output expected to decline more than 1 percentage point from the pre-crisis period and euro zone potential growth halving from 1.3\% to $0.7 \%$ (European Commission 2009b), risk for the potential growth of emerging economies that rely on Europe's capital inflows is more than apparent. Simulations performed by the IMF (2009a) suggested that the crisis could reduce medium-term growth between 0.6 to 2.5 percent and 0.4 to 2.2 percent for New Member States and other emerging economies, respectively. The IMF concluded that "while some of the developments affecting potential output are bound to correct themselves, others tie into long-standing European issues, such as high levels of employment protection and unrealized growth opportunities in the market for services, particularly in advanced economies (IMF 2009a)".

In 2013, within the European Economic Forecast for spring 2013, the European Commission included an explanation of whether the impact of the crisis on potential output estimated in 2009 (European Commission 2009b, referred above) is still valid (European Commission 2013). The forecast notes that the previous estimates were too optimistic in terms of the pace of the economic recovery. The new estimates show that the euro zone's potential output is expected to decline 1.3 percentage points (from $1.8 \%$ in $2003-2007$ to $0.6 \%$ in $2009-2013$ ) from the pre-crisis period (in comparison to the 2009 estimate of decline from $1.3 \%$ to $0.7 \%)$.

While there are several studies examining growth models and potential outputs and output gaps for a large group of countries, few include the Western Balkan countries (Darvas 2011, Becker et al 2010). Among the rare articles that include some of the Western Balkan countries is a 2011 paper by Turrini, Roeger, and Szekely. These authors analyze the growth potential of 56 advanced and emerging economies for the period of 1970-2008 (thus only backward looking data), including Albania, Croatia, Macedonia, and Serbia and Montenegro. They report the average GDP growth and the growth rate of potential output during periods with and without banking crises, and show that both in emerging and advanced economies, GDP growth during banking crises is almost half that during periods without financial distress and that potential output growth is also significantly lower (about 1\% in emerging countries).

The most recent review of potential output for the group of countries which includes the Western Balkans is the IMF's 2013 calculation of potential output for Central, Eastern, and South-Eastern Europe (IMF 2013b). They find that potential output growth fell from $5.2 \%$ in 2003-2008 to 1.7 in 2008-2012 and 2.3 in 2013-2017 in these countries, which represents a fall larger than in other emerging markets (other emerging markets had lower pre-crisis potential growth than Central, Eastern, and South-Eastern Europe, with a fall from around $4.5 \%$ to $4 \%$ ). It should be noted that these estimates by the IMF, due to data constraints, use varying methods for different countries (production function approach, structural VARs and statistical filtering techniques including the HP filter). Furthermore, out of the seven Western Balkan countries, potential output in this IMF report is estimated only for Croatia (showing a decrease in potential growth from $4.1 \%$ in $2003-2007$ to 
$1.1 \%$ in 2013-2017) and Bosnia and Herzegovina (showing a decrease in potential growth from 3.9\% in 2003-2007 to $2.2 \%$ in 2013-2017). While the periods covered in the analyses used by the IMF and in this paper (shown in Table 1 and in the discussion in the following sections of this paper) differ, the overall estimate of decline of potential growth is broadly comparable.

Given the scarcity of comparative studies of the potential output of the Western Balkan countries, this paper adds to the body of research by performing a calculation of the potential output and growth rates of the seven countries of the Western Balkans, thus enabling cross-country comparison and analyses of the average trends in the Western Balkans. Future research should be directed towards applying more sophisticated multivariate, growth accounting or DSGE methodologies for calculating potential outputs of the Western Balkan countries, given that the main limitation of this paper is the simplicity of the HP filter methodology being used.

\subsection{How is Potential Output Estimated?}

Since potential output (and thus the output gap as well) is an unobservable variable, and at the same time is also a variable used for numerous macroeconomic and fiscal analyses, several methodologies for the calculation of the potential output were developed. Measurement of the output gap, defined as the difference between the actual and potential output expressed as a share of potential output, is widely controversial in economic theory, reflecting the controversy and disagreement in the nature of economic cycles, since the potential output separates the trend from the cyclical component of the output (Cerra and Saxena 2000).

Several ways have been developed so far in order to calculate potential output indirectly. The methods of estimation vary in robustness and data requirement; hence, not all of them are equally suitable for all the countries. In general, there are three different types of approaches to estimation of potential output (Mishkin 2007). These are: i) aggregate approaches; ii) production function, or growth-accounting, approaches; and iii) dynamic stochastic general equilibrium (DSGE) approaches.

Aggregate approaches to estimating potential output are also referred to as top down approaches. These approaches normally use aggregate variables to derive measures of potential output (Mishkin 2007). The main assumption used in these calculations is if a change of an aggregate variable, such as employment or output, is sustainable, then it is also likely to be permanent. Subgroups of aggregate approaches include univariate and multivariate methods.

Univariate statistical methods are used to identify a permanent component of changes in output as a measure of potential output. For example, Beveridge and Nelson (1981), in an attempt to measure and date business cycles in the post-war US economy, identify a permanent component as a random walk drift, and the cyclical component as a stationary process with zero mean. As the decomposition methodology depends on past data (historical data or projections), it is computable in real time. Statistical detrending can be performed either by filtering or smoothing data series. Filtering equates to one-sided estimation and relies on backward information, and while it is often used for policy-making (Castle J. 2003), it is less accurate than smoothing (two-sided estimation) which uses both backward and forward information. For policy-making, smoothing requires forecast estimates.

Univariate methods include the Hodrick-Prescott filter, Baxter-King filter, Beveridge Nelson decomposition, and the Kalman filter (a description of different univariate and multivariate filters and production function approaches is given in Cotis, Elmeskov, and Mourougane 2005). The most frequently used univariate method is the HP filter. The HP filter is a pure mechanical smoothing procedure, whose statistical foundations are simple and transparent. According to the findings of an ad-hoc working group (European Commission 2001), established by the Economic Policy Committee to review estimation methods used by the European Commission and other national and international institutions, the HP filter 'does not require any judgmental assumptions nor reliance on any particular economic theory, and estimates from the HP filter can be easily and quickly replicated. These are the main reasons why the EC has relied on the HP filter for estimating trend output and the output gap in order to assess structural fiscal balances. There is little scope for countries to disagree with the details of the calculations. Overall, the advantages of using his method can be summed up as: allowing for stochastic shocks to the trend component; being simple, transparent and easily reproducible; and providing a uniform framework for many countries even in the presence of data availability issues (McMorrow and Roger 2001). In terms of shortcomings, besides the fact that HP filter de-trending can lead to spurious cyclicality and an excessive smoothing of structural breaks, the output gap estimates are also known to be affected by end-sample biases as the estimates of trend output tend to rely excessively on the latest developments in actual output (Cerra and Saxena 2000). This end-sample bias stems from the symmetric property of the HP filter, which requires that output gaps sum to zero over the estimation period. However, this problem can be partially overcome by using mediumterm growth projections (as this paper does, including the IMF projections up to 2018). In this case the extent of the bias will depend on the accuracy of the projections.

Generally, the main advantage of univariate methods is their simplicity and relatively modest data requirements. They provide a feel as to what potential output may be using a limited number of variables. The general disadvantage of these approaches, however, is that they require a variety of statistical assumptions and estimates related to these assumptions may vary significantly (McMorrow and Roger 2001). Another disadvantage is that the association of the movements of the permanent component of output with the stable inflation rate cannot be deduced, which is an obstacle for monetary economics' use of potential output (Mishkin 2007).

Having in mind the shortcomings of univariate aggregate approaches, multivariate aggregate approaches get 
more sophisticated and, rather than being purely statistical de-trending approaches (which statistically separate permanent from cyclical components of the time series data), they include information on structural relationships, using economic theory to separate structural and cyclical effects on level of economic activity (de Brouwer 1998). Multivariate approaches include the assumption developed by seminal works of Phelps (1967) and Friedman (1968), which state that economies in the long run steer towards the natural unemployment rate (the non-accelerating inflation rate of unemployment) associated with the long-run expected inflation level. Under multivariate approaches of calculating potential output, potential output corresponds to the nonaccelerating inflation rate of unemployment, while the output gap indicates whether inflation is expected to increase or decrease. Multivariate methods include the HodrickPrescott multivariate filter (HPMV filter), Beveridge Nelson multivariate decomposition, and Kalman multivariate filter (Cotis, Elmeskov, and Mourougane 2005). The main disadvantage of multivariate approaches is that they are based on certain assumptions of relationships between the variables used (as in Phillips Curve and Okun's Law). For example, the relationship between the unemployment gap and inflation must be correctly specified and all-encompassing, as well as the relationship between output and the unemployment gap, which is complicated by complex productivity and labor supply relations, while the natural rate of unemployment cannot be estimated without relative statistical uncertainty (Mishkin 2007). Thus, given the complex dynamics among variables, quantitative estimates of these relationships are prone to mistakes and misspecifications.

Production function approaches (also named growth accounting approaches) employ more sophisticated relationships from economic theory to derive potential output. These approaches examine different factors that influence potential growth, as opposed to looking at historical trends only (as is the case with the previous approaches), generating an estimate of potential output based on the assumption that all factors of production are utilized using more data than previous approaches (Mishkin 2007). Production function approaches include a full structural model, a production function with exogenous trends, and structural VAR. While the main advantage of these approaches is their narrower focus on different factors that drive potential output, their main shortcoming is the data gap in terms of labor, capital, and total factor productivity indicators for most countries. As an illustration of the data requirement in its simplest form, the growth-accounting framework requires data on labor productivity, even further decomposed into contributions of capital deepening, changes in labor quality, and the growth rate of multifactor productivity. Hence, in transition countries the application of this approach is virtually impossible due to data limitations. Furthermore, even for developed countries with robust data, the shortcoming of this approach is the difficulty of estimating the individual components of the growth accounting framework, since there is a large degree of uncertainty surrounding the estimates of growth accounting components (Cotis, Elmeskov, and Mourougane 2005). The growth rate of capital services is just one of the examples of variables that are difficult to measure.

Finally, by contrast to the conventional top-down approaches and production function-based approaches, the set of approaches based on dynamic stochastic general equilibrium (DSGE) gives a somewhat different perspective on the definition of potential output. The DSGE approaches are the most complex and most realistic approaches, since they allow for market imperfections (such as preference change, fiscal policy shocks, or terms of trade changes) to influence the level of potential output. In this context, the potential output is output level which would be achieved if the prices and wages were fully flexible so that the inflation is constant (Woodford 2003). Hence, if this approach is used, the potential output will fluctuate more, and output gaps will be smaller than in the case of traditional approach (Mishkin 2007), which has its disadvantages. The main shortcoming is that these approaches require estimation of model parameters of structural shocks, while from a policymaking stand point the DSGE approaches are problematic in the sense that they imply that most of the fluctuations are efficient and do not require policy measures (Cotis, Elmeskov, and Mourougane 2005). Compared to the first two sets of approaches, the third set of approaches requires even more data, most of which is not readily available and is often estimated by the researchers.

Severe data constraints (either the lack of data or lack of time-series records of data) limit the possibilities for calculation of the potential output for the Western Balkan countries, in particular in terms of structural relationship methodologies. Therefore, the plausible methodology to be applied to calculate the potential output of the Western Balkan countries is statistical de-trending - an aggregate univariate approach. This paper uses the HP filter - one of the most prominent univariate methods of potential output estimation, given its relative simplicity and low demands in terms of data availability.

\section{METHODOLOGY}

As discussed in the previous Section, due to data constraints in terms of structural relationship methodologies, this paper is limited to using the simple statistical de-trending methodology of the Hodrick-Prescott filter. It is the most known and commonly used of univariate methods of potential output estimation in both academic research and by international organizations such as the IMF, OECD, European Commission and European Central Bank (Ladiray, Mazzi, and Sartori 2003), given its relative simplicity and low demands in terms of data availability. This methodology uses a longrun symmetric, moving average to de-trend GDP data. In essence, the main intuition is that the HP filter extracts a trend component by introducing a tradeoff between a good fit to the actual series and the degree of smoothness of the trend series (Cotis, Elmeskov, and Mourougane 2005). For the purpose of this paper, in line with the traditional approach, the potential output is understood to be a trend output. 
While there are downsides of mechanical de-trending in Hodrick and Prescott's approach that could result in spurious cycle reporting and over-smoothing (a description of the properties and shortcomings of the HP filter are given in Harvey and Jaeger, 1993) the HP filter is the most popular method for the derivation of potential output due to its flexibility in identifying fluctuations in trend output (Cerra and Saxena 2000). Moreover, if used with discretion, it 'yields extremely fast results and can prove very useful for the initial, exploratory analysis of time series' (Pedregal and Young 2001).

In terms of actual calculation, the HP filter assumes that the actual output, $Y_{t}$ is composed of a trend component $Y^{*}$ and a cyclical component $C_{t}$.

$$
Y_{t}=Y^{*}+C_{t}
$$

The HP filter is used to isolate the $C_{t}$ by minimizing the sum of the term determining goodness of the fit and the term determining smoothness on the assumption that the average value of the cycle component is zero over longer intervals of time, thus deriving at trend output $Y^{*}$ by minimizing a combination of the gap between the actual output and trend output and the rate of change in trend output for the entire observation sample T (Cerra and Saxena 2000). In other words, the filter, which is a two-sided symmetric moving average filter, minimizes the following objective function:

$$
\sum_{t=1}^{T}\left(Y_{t}-Y_{t}^{*}\right)^{2}+\lambda \sum_{t=2}^{T-1}\left[\left(Y_{t+1}^{*}-Y_{t}^{*}\right)-\left(Y_{t}^{*}-Y_{t-1}^{*}\right)\right]^{2}
$$

Here, the first term estimates the time series' fitness and the second term estimates the smoothness. The obtained trends balance the first to the original series against the degree of smoothness. The term $\lambda$ - Lagrange multiplier - is a positive number which penalizes variability in the growth component series (Hodrick and Prescott 1981). Parameter $\lambda$ controls the smoothness of the trend (the trend component approaches a linear trend as $\lambda$ approaches infinity, while at $\lambda=0$ the trend component equals to the actual series). In other words, the filter de-trends the data by solving a least square problem, i.e. minimizing the sum of squares of the transitory component subject to a penalty parameter $\lambda$ for the variations in the second differences, with the minimization resulting in a TxT matrix of linear equations for the serjes for the series $Y_{t}$ as a function of the trend component $Y^{*}$ (Ladiray, Mazzi, and Sartori 2003).

The choice of the value of parameter $\lambda$ is determined by the frequency of time series. Commonly used values of $\lambda$ are 100 for annual data (which is used in this paper), 1,600 for quarterly data, and 14,400 for monthly data. The parameter $\lambda$ is chosen somewhat arbitrarily and the above values have been popularized by the academic literature on real business cycles.

\section{DATA AND RESULTS}

This paper uses secondary data and projections on real GDP levels and growth rates for the period 2000-2018 for the seven Western Balkan countries from the International Monetary Fund's World Economic Outlook (WEO) Database from October 2013 (IMF 2013a). The seven Western Balkan countries (Albania, Bosnia and Herzegovina, Croatia, Kosovo, Macedonia, Montenegro, and Serbia) are chosen given that the region is inter-connected not only through historical and geographical bounds, but also through current connections through trade among the countries, as well as similar economic growth models in most cases. These countries are also frequently grouped in one category by international organizations - for example the World Bank groups them as south-eastern Europe, with the recent exclusion of Croatia, due to its 2013 EU membership.

Figures 1 to 7 (given at the end of the article) show GDP gap (the percentage difference between the absolute values of real GDP and the HP trend of absolute values of real GDP calculated using equation 2) and real GDP growth rates in comparison to average HP trend for GDP growth (calculated as the HP trend of real GDO growth rates using equation 2) for each of the seven Western Balkan countries during the 2001 to 2018 period. While the HP filter methodology used in this paper has its limitations (as mentioned in the previous section of the paper), the estimates of potential growth loss in this paper (shown in Figures 1-7 and Table 1) are broadly in line with the IMF's recent calculation of the potential output loss for Central, Eastern and South-Eastern Europe which include some of the Western Balkan countries (IMF 2013b, explained above in the section on review of the research). Moreover, the estimated results are intuitively plausible. 
Figure 1: GDP Gap and Real GDP Growth for Albania
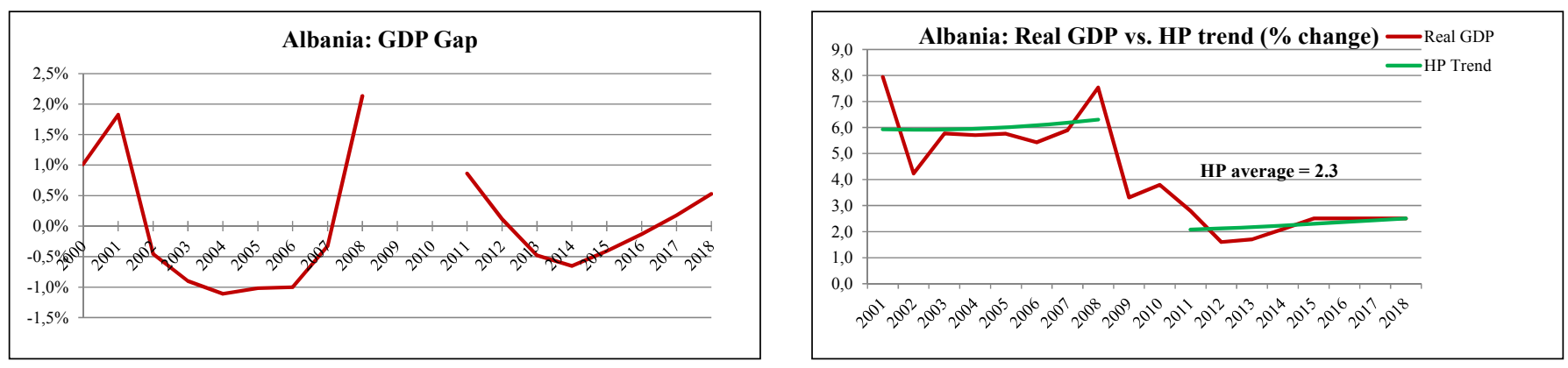

Source: Own calculations based on data from the International Monetary Fund's World Economic Outlook from October 2013

Figure 2: GDP Gap and Real GDP Growth for Bosnia and Herzegovina (BiH)
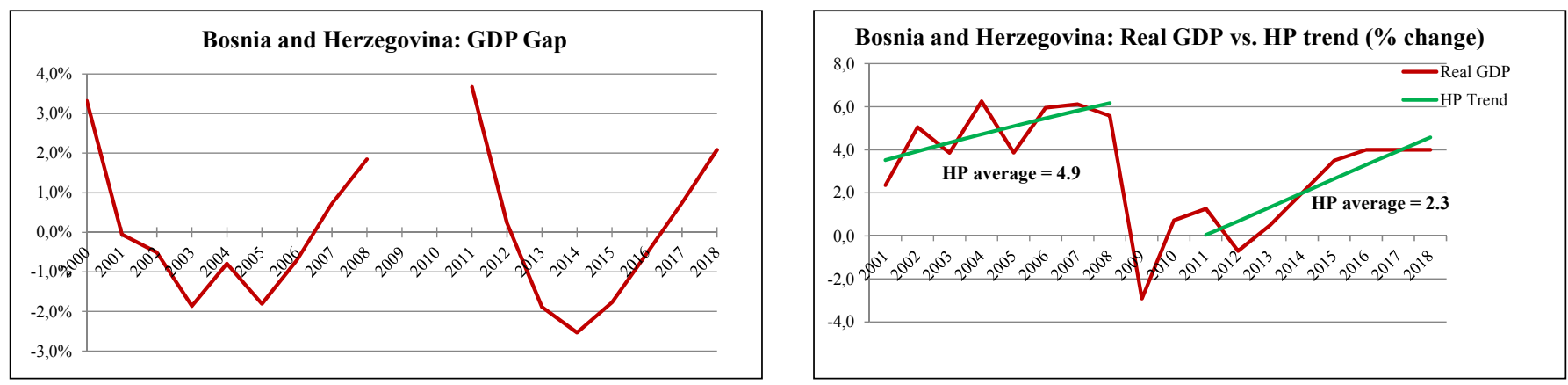

Source: Own calculations based on data from the International Monetary Fund's World Economic Outlook from October 2013

Figure 3: GDP Gap and Real GDP Growth for Croatia
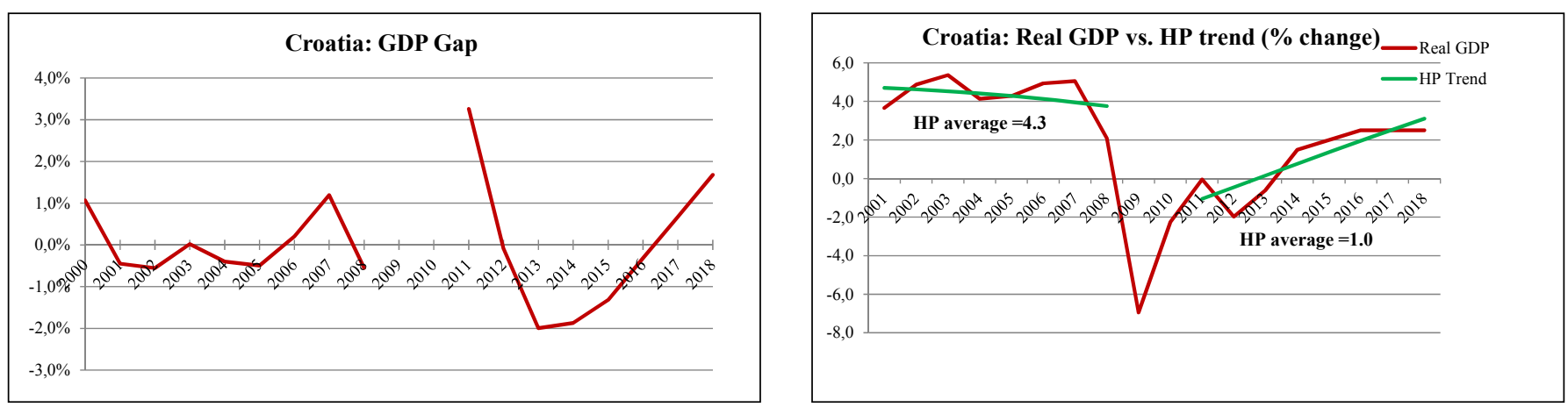

Source: Own calculations based on data from the International Monetary Fund's World Economic Outlook from October 2013 
Figure 4: GDP Gap and Real GDP Growth for Kosovo
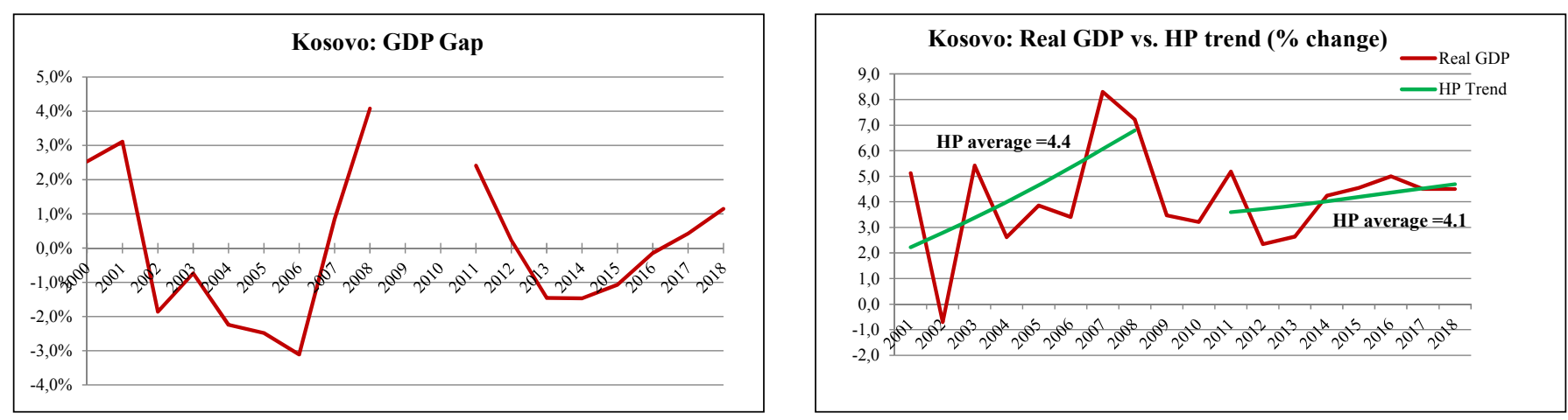

Source: Own calculations based on data from the International Monetary Fund's World Economic Outlook from October 2013

Figure 5: GDP Gap and Real GDP Growth for Macedonia

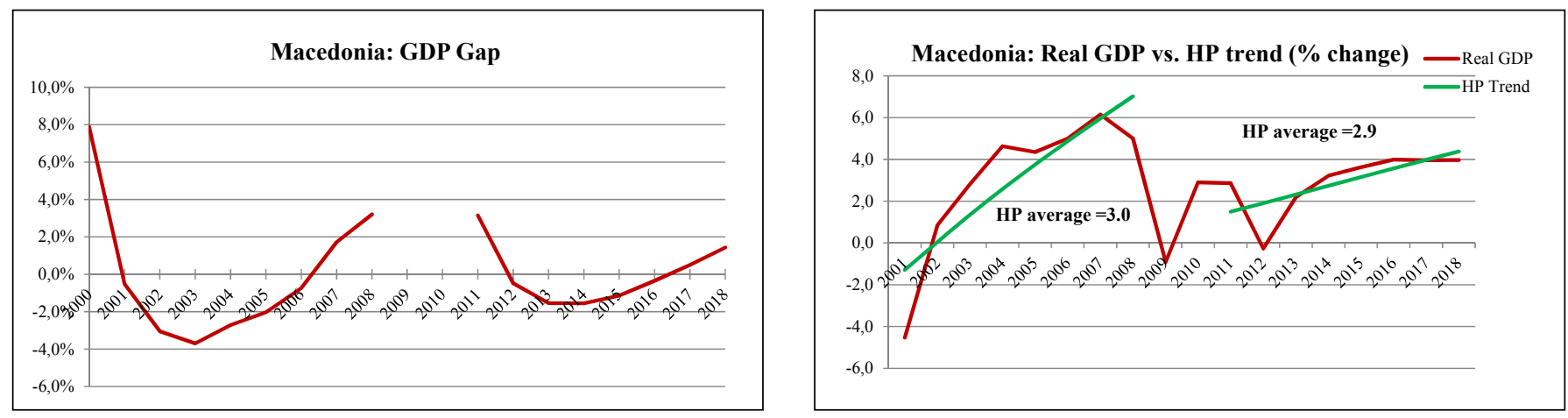

Source: Own calculations based on data from the International Monetary Fund's World Economic Outlook from October 2013

Figure 6: GDP Gap and Real GDP Growth for Montenegro
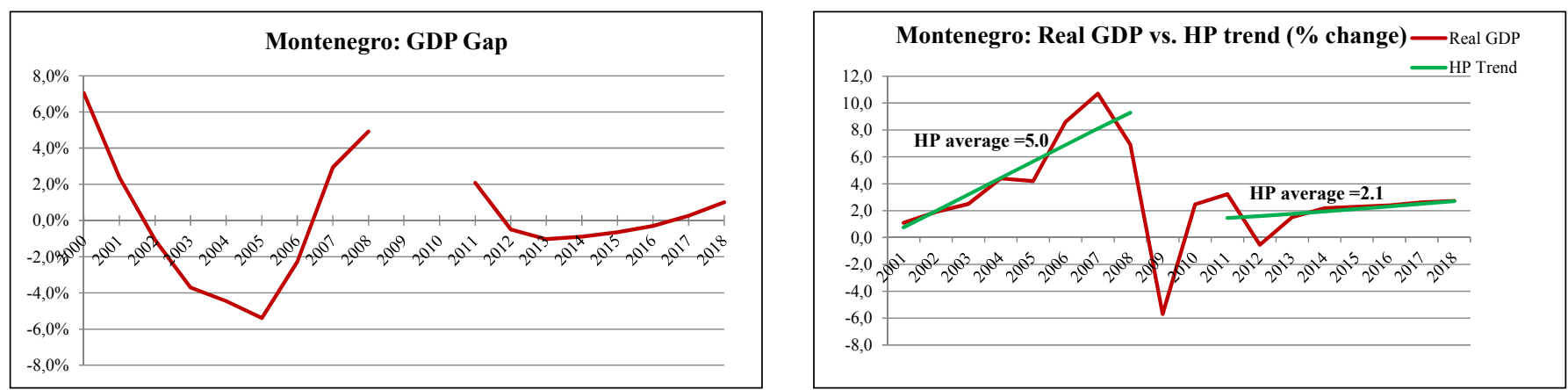

Source: Own calculations based on data from the International Monetary Fund's World Economic Outlook from October 2013

Figure 7: GDP Gap and Real GDP Growth for Serbia

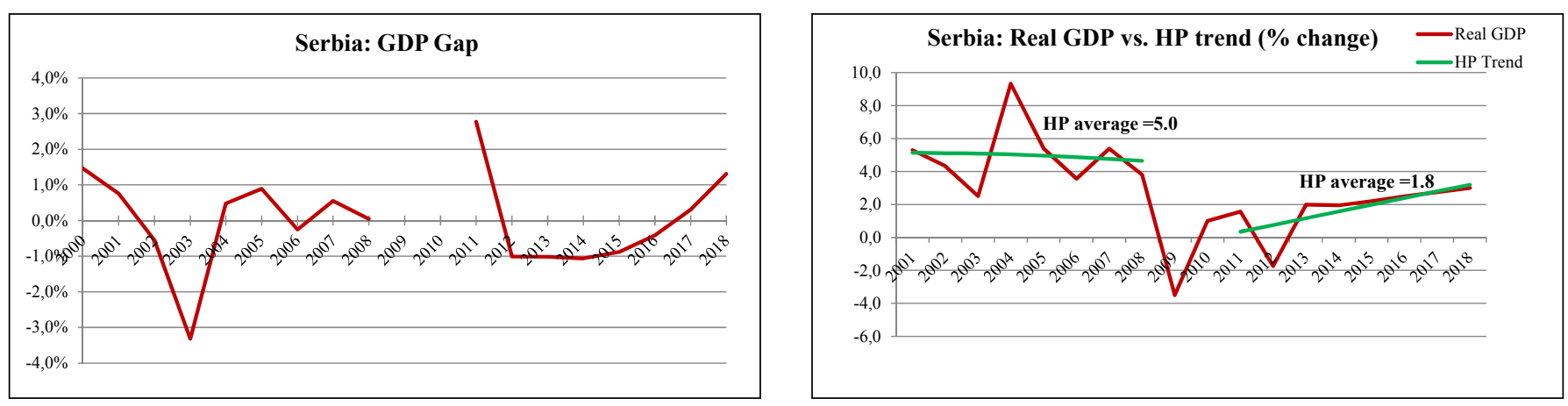

Source: Own calculations based on data from the International Monetary Fund's World Economic Outlook from October 
Estimating potential output of a country is useful in defining sustainable growth levels and in determining whether the macroeconomic policy of that country should be more geared towards demand stimulation (in the case of a large gap between potential and real GDP, implying that the production factors in the economy are not utilized well) or structural reforms (in cases where the gap between potential and real GDP is exhausted and the economy needs underlying change to the growth model). Table 1 (given at the end of the article) shows potential real GDP growth rates derived from the average HP trend for each of the countries for the two periods. The 2001-2008 and 2011-2018 HP trend figures shown in Table 1 represent average HP trends for average potential real GDP growth rates for these periods, which are shown in Figures 1-7 next to the annual HP trends in text boxes (in other words, the text boxes in Figures 1-7 show the average of the annual HP trends for these two periods, which are also summarized in Table 1).

For the purpose of this paper, 2001-2008 is looked at as the pre-crisis period and 2011-2018 as the post-crisis period. The years of 2009 and 2010 were selected to serve as a "crisis period" for the purpose of this paper; the two four-year cycles prior to this primary crisis period served to examine potential output trends before the crisis, and the two four-year cycles after this primary crisis period served to examine potential output trends after the crisis. This is a frequently used approach in which a specific period is taken out of analysis to compare the estimates prior to that period to those following that period - for example, the European Commission in its latest potential output calculations uses 2003-2007 and 2009-2013 for comparison, leaving out 2008, which was the year of the most severe downturn in the euro area (European Commission 2013). It needs to be noted that for most of the countries year 2012 was also a year in which GDP reduction was recorded as the result of the sovereign debt crisis in the euro zone, but given its relatively shorter length, 2012 remains included in the post-crisis period for the purpose of this paper.

As expected, the results point to the strong decrease in the post-crisis potential output relative to pre-crisis levels due to crisis-related contraction of both domestic demand and export demand for the WB countries. In fact, on average for the seven WB countries, potential real GDP growth has halved, showing a decrease of $49 \%$ from a $4.7 \%$ average potential pre-crisis real GDP rate to a $2.4 \%$ average potential post-crisis real GDP rate.

More specifically, Table 1 shows estimates that average annual HP trend, calculated as explained in the previous section (equation 2) based on real GDP growth rates in 2001-2008 (column 2 of Table 1) and 2011-2018 (column 3 of Table 1) and noting that 2013-2018 data consists of projections, is between $77 \%$ and $3 \%$ lower in the post-crisis period.

Looking at individual countries:

- for Albania average potential growth in 2001-08 was $6 \%$ and is $2.3 \%$ for $2011-18$,

- for $\mathrm{BiH}$ average potential growth in 2001-08 was $4.9 \%$ and is $2.3 \%$ for $2011-18$,

- for Croatia average potential growth in 2001-08 was $4.3 \%$ and is $1 \%$ for $2011-18$,

- for Kosovo average potential growth in 2001-08 was $4.4 \%$ and is $4.1 \%$ for $2011-18$,

- for Macedonia average potential growth in 2001-08 was $3 \%$ and is $2.9 \%$ for $2011-18$,

- for Montenegro average potential growth in 2001-08 was $5 \%$ and is $2.1 \%$ for $2011-18$, and

- for Serbia average potential growth in 2001-08 was $5 \%$ and is $1.8 \%$ for $2011-18$.

Thus, for the majority of the Western Balkan countries - Albania, BiH, Croatia, Montenegro, and Serbia, which together comprise around $90 \%$ of the total Western Balkan countries (IMF WEO data, October 2013) - post-crisis potential output growth is between $53 \%$ and $77 \%$ lower than in the pre-crisis period (column 4 in Table 1). Although they are also estimated to have lost potential output growth in the post-crisis period, Macedonia and Kosovo are somewhat different in that they show relatively small estimated potential output loss (3\% for Macedonia and 7\% for Kosovo). This may be explained by the following facts: Macedonia and Kosovo experienced relatively low GDP growth in 2001-2008

Table 1: Potential Real GDP Growth Rates for Western Balkan Countries

\begin{tabular}{|c|c|c|c|}
\hline & HP trend $2001-2008$ & HP trend 2011-2018 & \% Change \\
\hline 1 & 2 & 3 & $4=(3-2) / 2$ \\
\hline Albania & $6.0 \%$ & $2.3 \%$ & $-62 \%$ \\
\hline Bosnia and Herzegovina & $4.9 \%$ & $2.3 \%$ & $-53 \%$ \\
\hline Croatia & $4.3 \%$ & $1.0 \%$ & $-77 \%$ \\
\hline Kosovo & $4.4 \%$ & $4.1 \%$ & $-7 \%$ \\
\hline Macedonia & $3.0 \%$ & $2.9 \%$ & $-3 \%$ \\
\hline Montenegro & $5.0 \%$ & $2.1 \%$ & $-58 \%$ \\
\hline Serbia & $5.0 \%$ & $1.8 \%$ & $-64 \%$ \\
\hline AVERAGE & $4.7 \%$ & $2.4 \%$ & $-49 \%$ \\
\hline
\end{tabular}

Source: Own calculations based on data from the International Monetary Fund's World Economic Outlook from October 2013 
compared to the rest of the Western Balkans, partially due to less open economies in terms of foreign capital inflow and international trade; they did not experience average growth reduction in 2009-2010; and they have the highest growth/ growth projections for 2011-2018. Real GDP trends for all countries are shown in Figures 1-7. The order of magnitude of the potential output loss for all seven countries is also broadly (for the most part) in line with the order of their development in terms of GDP per capita in purchasing power parity, thus implying that some countries are farther from the process of catching up with developed countries than others, so it is plausible that for those countries a smaller potential output loss is estimated (for example, the difference between the most developed country, Croatia, versus the least developed, Kosovo).

Based on calculated pre-crisis and post-crisis potential GDPs and GDP gaps for the Western Balkan countries, significant potential output losses took place. This implies that since they are faced with slowed potential output growth, the Western Balkan countries need to implement structural economic reforms in order to support long-term production and employment growth (as is also the case in the euro area, as discussed by the European Central Bank (2011)). This fall in the post-crisis potential growth rate of the WB economies, which results in domestic output remaining permanently below pre-crisis trends, is in line with the findings in other literature (e.g. IMF 2013b).

In other words, the results which show a decrease in potential growth rates (Table 1 and Figures 1-7), imply that since the crisis has exacerbated and put additional spot light on the internal weaknesses of the economies in the Western Balkans, it is not likely that the governments of the Western Balkan countries will be able to achieve strong growth rates comparable to the pre-crisis period solely by improving the utilization of existing production factors at their current technology level, but that structural reforms will need to be implemented to change the underlying growth model.

In terms of a possible policy focus for the structural reforms, countries may want to consider areas of economic weaknesses (common for most of the WB countries) such as: over-reliance on private consumption and foreign capital inflows; weak investments and sub-optimal business environments; growing public debt and the sub-optimal efficiency and effectiveness of the public sector; the high indebtedness of the private sector; and significant structural weaknesses in labor markets.

\section{CONCLUSIONS}

This paper aims to contribute to the discussion on whether recent crises led to the impairment of the Western Balkan economies' potential output over the medium term. Due to data constraints, the simple aggregate univariate HP filter approach is followed to investigate whether potential output levels tend to be different in the aftermath of the crises compared to the pre-crisis period. The results point to the strong decrease (with potential real GDP growth rate being roughly halved on average for the WB countries) in post-crisis potential output relative to pre-crisis potential output - on average for the seven WB countries, potential real GDP growth has halved, showing a decrease of $49 \%$ from $4.6 \%$ average potential pre-crisis real GDP rate to a $2.4 \%$ average potential post-crisis real GDP rate.

Since estimating the potential output of a country may indicate whether the demand stimulation (in the case of a large gap between potential and real GDP, implying that the production factors in the economy are not utilized well) or structural reforms (in a case where the gap between potential and real GDP is exhausted and the economy needs underlying changes to its growth model) are more appropriate, the estimates of the shrinking potential output of the Western Balkans laid out in this paper may imply that structural economic reforms are needed in order to support sustainable long-term production and employment growth.

\section{REFERENCES}

Becker T., Daianu D., Darvas Z., Gligorov V., Landesmann M., Petrovic P., Pisani-Ferry J., Rosati D., Sapir A., Weder di Mauro W. 2010. Whither growth in central and Eastern Europe? Policy lessons for an integrated Europe. Bruegel Blueprint Series. Vol 11.

Beveridge, S. and Nelson, C. R. 1981. A New Approach to Decomposition of Economic Time Series into Permanent and Transitory Components with Particular Attention to Measurement of the 'Business Cycle. Journal of Monetary Economics, vol. 7: 151-74.

Borio, C., Disyatat P. and Juseluis M. 2013. Rethinking Potential Output: Embedding Information about the Financial Cycle. BIS Working Papers No. 404.

Campbell, John Y., and N. Gregory Mankiw. 1987. Permanent and Transitory Components in Macroeconomic Fluctuations. American Economic Review 77, No. 2: 111-117.

Castle, J. 2003. Measuring Excess Demand and its Impact on Inflation. MPhil. Thesis. University of Oxford.

Cerra, V. and Saxena, C.S. 2000. Alternative Methods of Estimating Potential Output and the Output Gap: An Application to Sweden. International Monetary Fund Working Paper No 00/59.

Cerra, V. and Saxena, C.S. 2008. Growth Dynamics: The Myth of Economic Recovery. American Economic Review, 98(1): 439-457.

Cotis J.P, Elmeskov J. and Mourougane A. 2005. Estimates of potential output: Benefit and pitfalls from a policy perspective. In L. Rechling (Ed.) 2005. Euro area business cycle: stylized facts and Measurement issues. CEPR: London.

Darvas Z., 2011. Beyond the Crisis: Prospects for Emerging Europe. Comparative Economic Studies 53: 261-290.

De Brouwer G. 1998. Estimating Output Gaps. Research Discussion Paper 9806, Reserve Bank of Australia.

De Masi, P.R. 1997. IMF Estimates of Potential Output: Theory and Practice. International Monetary Fund Working Paper No 97/177. Washington, DC.

Edge, R. M., Kiley, M. T. and Laforte, J-P. 2007. Natural Rate Measures in an Estimated DSGE Model of the U.S. Economy. Finance and Economics Discussion Series 2007-8. Washington, DC: Board of Governors of the Federal Reserve System. 
European Bank for Reconstruction and Development 2009. Transition Report 2009: Transition in Crisis.

European Central Bank 2011. Trends in potential output. Monthly Bulletin, pp. 73-85.

European Commission 2001. Report on Potential Output and Output Gap, Economic Policy Committee, Report No ECFIN/ EPC/670/01/en, Brussels.

European Commission 2009a. Spring Forecast 2009. European Economy 3.

European Commission 2009b. Quarterly Report on the Euro Area, Vol. 8, No. 2.

European Commission 2011a. 2011 Pre-Accession Economic Programs of Candidate Countries: EU Commission Assessments. European Economy Occasional Papers 80.

European Commission 2011b. 2011 Pre-Accession Economic and Fiscal Programs of Potential Candidate Countries: EU Commission Assessments. European Economy Occasional Papers 81.

European Commission 2013. Spring Forecast 2013: The EU Economy: Adjustment Continues. European Economy 2, 2013.

Friedman, M. 1968. The Role of Monetary Policy. American Economic Review, 58 (March): 1 - 17.

Fueki, T., Fukunaga, I., Ichiue, H. and Shirota, T. 2010. Measuring Potential Growth with an Estimated DSGE Model of Japan's Economy. Bank of Japan Working Paper Series No. 10 - E - 13.

Gibbs, D. 1995. Potential Output: Concepts and Measurement. New Zealand Department of Labor Market Bulletin 1995 No. 1:71-115.

Harvey, A. C. and Jaeger, A. 1993. Detrending, Stylized Facts and the Business Cycle. Journal of Applied Econometrics, 8(3): 231-247.

Hodrick R. J. and Prescott E. C. 1981. Post-War U.S. Business Cycles: An Empirical Investigation, Discussion Paper No. 451. The Center for Mathematical Studies in Economics \& Management Sciences, Carnegie-Mellon University.

International Monetary Fund 2009. Regional Economic Outlook: Europe - Securing Recovery. Washington, DC: International Monetary Fund.

International Monetary Fund. 2009a. World Economic Outlook: Sustaining the Recovery. Washington, DC: International Monetary Fund.

International Monetary Fund. 2011. Working Paper: The Impact of the Global Crisis on South-Eastern Europe. Washington, DC: International Monetary Fund.
International Monetary Fund 2012. World Economic Outlook Update: Global Recovery Stalls, Downside Risks Intensify. Washington, DC: International Monetary Fund.

International Monetary Fund. 2013a. World Economic Outlook: Transitions and Tensions. Washington, DC: International Monetary Fund.

International Monetary Fund 2013b. Regional Economic Issues: Central, Eastern, and South-eastern Europe. Washington, DC: International Monetary Fund.

Jahan, M., Mahmud A. S. 2013. What is the Output Gap, International Monetary Fund Finance \& Development Vol 50, No. 3, Washington, DC: International Monetary Fund. http:// www.imf.org/external/pubs/ft/fandd/2013/09/basics.htm (accessed February 22, 2014).

Kuttner, K. 1994. Estimating Potential Output as a Latent Variable. Journal of Business and Economic Statistics Vol. 12, Issue 3. Alexandria, VA: American Statistical Association.

Ladiray D., Mazzi, G. L., \& Sartori, F. 2003. Statistical Methods for Potential Output Estimation and Cycle Extraction. Working Papers and Studies, Eurostat.

Mc Morrow K. \& Röger W. 2001. Potential Output: Measurement Methods, "New" Economy Influences and Scenarios for 20012010, ECFIN Economic Paper No 150

Mishkin, F. S. 2007. Estimating Potential Output, Speech at the Conference on Price Measurement for Monetary Policy. May 24, 2007. Federal Reserve Bank of Dallas, Dallas, Texas.

Parigi, S. and Siviero S., 2001. Economic Modeling Vol. 18: 525-550.

Pedregal, D.J., and Young, P.C. 2001. Some Comments on the Use and Abuse of the Hodrick-Prescott Filter, Review on Economic Cycles No. II.

Phelps, E. S. 1967. Phillips Curves Expectations of Inflation, and Optimal Inflation over Time. Economica, 34: 254 - 81.

Turrini, A., Roeger W. and Szekely, I.P. 2011. Banking Crisis, Output Loss, and Fiscal Policy. CESifo Economic Studies.

World Bank. 2010. Supporting Structural Reforms Needed for Increasing Competitiveness in the Western Balkans. Presentation at IPA 2010 Conference: Sustainable Results and Impacts, Brussels, December $6^{\text {th }} 2010$.

Woodford, M. 2003. Interest and Prices: Foundations of a Theory of Monetary Policy. Princeton University Press. 